\title{
Writing and Daydreaming
}

\author{
Hazel Morrison
}

Abstract This chapter was conceived during an interdisciplinary psychological experiment, in which geographer Hazel Morrison asked participants to record and describe in face-to-face interviews their everyday experiences of mind wandering. Questions abound concerning the legitimacy of interviewee narratives when describing subjective experience, and the limits of language in achieving 'authentic' description. These concerns increase when looking at mind-wandering experiences, because of the absence of meta-cognition during periods of self-generated thought. Here, Hazel explores the tensions at play in twentieth-century discourses around the self, fantasy and expression.

Keywords Anna Freud . Mind wandering · Psychoanalysis · Selfrepresentation · Sigmund Freud · Virginia Woolf

The experience of mind wandering - which tends, now, to be placed by the discipline of psychology under the umbrella term 'self-generated thought', along with associated states such as daydream, fantasy and reverie - is recognized as a ubiquitous component of everyday life. ' '[I]n day-dreaming',

\footnotetext{
H. Morrison $(\bowtie)$

Durham University, Durham, United Kingdom

e-mail: hazel.morrison@durham.ac.uk

(C) The Author(s) 2016

F. Callard et al. (eds.), The Restless Compendium, DOI 10.1007/978-3-319-45264-7_4
} 
wrote Jerome Singer, 'all of us are in a sense authorities because of the very private nature of our experiences'. ${ }^{2}$ Yet when looking to the history of psychological research that underpins contemporary understandings of mind wandering, 'all of us', that is, the generic you and I who experience our minds wandering every day, are notably absent. This isn't to say that the voices, experiences and narratives of everyday people are entirely obscured. Rather the reliability - or, one might say, the authority - of the subjective viewpoint is repeatedly denigrated. ${ }^{3}$

This, argue Schooler and Schreiber, is because although our experience of mind wandering is in itself undeniable, our ability to accurately represent our experience is frequently inadequate. ${ }^{4} \mathrm{~A}$ momentary loss of 'meta-cognition', or self-reflexive awareness of our mental state, is commonly recognized to characterize the transition to the mind wandering state. ${ }^{5}$ And if we are unable to recognize our minds having wandered, the validity of our accounts of these fugitive mental processes must be questionable. There are historical precedents to this problematic. The psychologist William James, for example, famously compared the attempt to capture such fleeting subjectivity as that of grasping 'a spinning top to catch its motion, or trying to turn up the gas quickly enough to see how the darkness looks'. 6

I agree that the aforementioned denigration of the authority of subjective experience may be traced to this long-standing issue of meta-cognition, and its absence during periods of mind wandering. However, James recognized a second impediment to introspection, which, until recently, has received little attention within mainstream psychology. This he identified as the limitation of language, claiming an 'absence of a special vocabulary for subjective facts', which hindered the study of all 'but the very coarsest of them'. ${ }^{7}$ More than a century on, Callard, Smallwood and Margulies, in a commentary on scientific investigations of the mind at 'rest', recognize a similar problematic. A 'historical bias', they write, 'toward explicating external processing has meant the psychological vocabulary for describing internally generated mental content is relatively stunted. ${ }^{8}$ Nonetheless, they suggest there exist pockets of literature, now 'largely unknown or disregarded in cognitive psychology' which once used heterogeneous methods to study and elicit states of 'daydream, fantasy, mind wandering and dissociation'?

To bring some of these methods to greater visibility, this chapter looks back to the period 1908-23, a period during which daydream and fantasy were experimentally explored through diverse introspective practices, 
ranging from the free association methods of psychoanalysis to stream of consciousness literary techniques. Reading Sigmund Freud's famous essay 'Creative Writers and Day-Dreaming' (1908), in relation both to his daughter Anna Freud's essay 'The Relation of Beating-Phantasies to a Day-Dream' (1923) and to Virginia Woolf's short story 'The Mark on the Wall' (1919), this chapter explores the place of writing within complexes of daydream and fantasy. These interconnected texts make clear the complexities of articulating inner, mental phenomena through the medium of the written word. In so doing, they offer additional paths through which we might understand why the subjective viewpoint has often been denigrated or downplayed within the history of daydreaming and mind wandering research. ${ }^{\mathrm{i}}$

\section{Multiplicity of the Self AND the Fragility of Self-Representation}

Sigmund Freud's essay 'Creative Writers and Day-Dreaming' (1908) is known for its long-standing contribution to studies of daydream and fantasy, phenomena now frequently brought into confluence with mind wandering. ${ }^{10}$ Freud recognized imaginative activities such as daydreaming, 'phantasy' and building 'castles in the air' as normal human behaviour. Yet despite the ubiquitous nature of daydreaming, he understood it to necessitate concealment. ${ }^{11}$

Why? Freud identified socially unacceptable egoistic and erotic wishes as significant motive forces that furnish the contents of fantasy and daydream. Freud wrote of the 'well-brought-up young woman' being 'allowed a minimum of erotic desire', and of the young man who must learn to subdue an 'excess of self-regard' to gain acceptance in society. At the extreme, to allow one's daydreams to become 'over-luxuriant' and overpowerful was seen to risk the onset of 'neurosis or psychosis' ${ }^{12}$

Only the creative writer, argued Freud, was uniquely able to articulate 'his [sic] personal daydreams without self-reproach or shame'. The aesthetic qualities of prose were seen by Freud to 'soften', 'disguise' and sublimate the egotistical elements of the daydream, allowing author and reader alike covert indulgence in the pleasure of fantasizing. ${ }^{13}$ ii

\footnotetext{
${ }^{i}$ See Chap. 5.

${ }^{\text {ii }}$ Cf. Chap. 7.
} 


\section{Creativity, Self and Sublimation: 'The Mark on the Wall'}

Virginia Woolf's short story 'The Mark on the Wall' (1919) exemplifies the skill of the creative writer in giving expression to daydream, reverie and fantasy. Like Freud, Woolf recognizes the commonality of the experience of daydreaming: even the most 'modest mouse-coloured people', claims the narrator, cherish moments of self-referential imaginative indulgence, despite believing 'genuinely that they dislike to hear their own praises.' 14 Moreover, Woolf's text addresses how, for daydream and fantasy to be freely expressed, the writer must deploy tactics of disguise and deflection.

Woolf's experimental approach to depicting inner monologue mimics the rhythms and effects of the wandering mind, as her writing gravitates from domestic space towards thoughts of childhood fancy. The sight of burning coals evokes description of a 'calvacade of red knights ... an old fancy, an automatic fancy, made as a child perhaps'. Distracted, her thoughts 'swarm upon a new object': a poorly perceived mark, 'black upon the white wall ...'. Rich and humorous, her prose flits from some current impression (a bowl, flower, cigarette smoke) to self-referential thoughts and fantasies. Intermittently her train of thought returns to the mark on the wall: lifting this new object up 'as ants carry a blade of straw so feverishly', before leaving it to be picked up later, afresh. ${ }^{15}$

While Woolf's text meanders, and on occasion tumbles, from one thought to the next, a succession of passages offers the opportunity to reflect on the thought processes that permit fantasized, egotistical self-expression. 'I wish I could hit upon a pleasant track of thought', states the narrator, 'a track indirectly reflecting credit upon myself'. These, she continues, 'are not thoughts directly praising oneself'. Rather, they express indirectly a figure of self, 'lovingly, stealthily ... not openly adoring'. This, declares Woolf's narrator, 'is the beauty of them'. ${ }^{16}$

Woolf portrays daydreaming as a mode of thought that allows for the creation of a sense of self invested with depth, colour and romance. Yet the author also recognizes an inherent danger in giving voice to daydream and fantasy. Woolf's text hints at deep motivations for concealment and sublimation, for like Freud, she writes of the urge to protect the idealized self-image from the gaze of the external world. If this idealized self-image were to be openly recognized, its integrity would become threatened. To have one's fantasized sense-of-self disappear is, for the narrator, to become 
'only a shell of a person', as seen by others. Indeed, writes Woolf, 'what an airless, shallow, bald, prominent world it becomes!' ${ }^{17}$

For the protagonist of the story, the destruction of an inner self-image that exists within the realm of fantasy is a genuine threat. Fear lies with the potential for 'idolatry', for a sense of self being 'made ridiculous, or too unlike the original to be believed in any longer'. In this sense, Woolf's short story suggests why daydream, fantasy and mind wandering are states of mind that resist introspective redescription: to give self-expression to the wandering mind is to risk damaging the inner self. Writing, I suggest, emerges as a crucial intermediary for Woolf, through which the fantasized self may be given self-expression. ${ }^{18}$

\section{Fragmentation}

[I]n the daydream each new addition or repetition of a separate scene afford[s] anew opportunity for pleasurable instinctual gratification. In the written story $\ldots$ the direct pleasure gain is abandoned. ${ }^{19}$

Anna Freud - as the quotation above from her essay 'The Relation of Beating-Phantasies to a Day-Dream' (1923) indicates - offers another model for the complex relationship between daydreaming, subjectivity and writing. In this essay, she presents the case of a young female patient, characterized by a strong propensity to daydream. The girl, Anna Freud writes, had a history of fantasy thinking in which two polarized thought patterns dominated. By encouraging the girl, during analysis, to express the contents of these daydreams, Anna Freud explores how processes of repression and transformation link the inner daydream to its articulation in the 'real' world. ${ }^{20}$ In doing so, she postulates more precisely than Sigmund Freud how daydreaming experience is transformed and transfigured once communicated through the written word.

In Anna Freud's essay, the girl's early fantasies of beating are shown to have culminated in masturbatory climax. As the girl aged, these fantasies were increasingly repressed as the girl associated them with shame and displeasure. The girl was then reported to have developed seemingly converse daydreams, which she labelled 'nice stories'. These are understood by Anna Freud as the transformation of the beating fantasy into stories acceptable to the girl's sense of morality, which yet enable a similar degree of pleasurable gratification. 
In both the beating fantasies and 'nice' daydreams, Freud relates that the girl 'did not feel bound to work out a logical sequence of events' of the kind that would characterize a written narrative. Rather she scanned forward and back to differing phases of the tale; she might 'interpose a new situation between two already completed and contemporaneous scenes', to the extent that the 'frame of her stories was in danger of being shattered'. ${ }^{21}$ Each repetition and addition to the daydream was understood to enable renewed opportunity for 'pleasurable instinctual gratification'. Yet when the daydream became 'especially obtrusive', the girl turned to writing, reportedly 'as a defence against excessive preoccupation with it'. ${ }^{22}$

Anna Freud noted a sharp difference between the unbridled, multi-layered sequence of events that made up the daydream, and the structured, novelistic quality of daydreams transformed into a written story. ${ }^{i i i}$ No longer a series of overlaid, repetitive episodes, culminating time and again in pleasurable climax, once written down the 'finished story' reportedly did 'not elicit any such excitement' as during the experiencing of the daydream. Yet this, concluded Anna Freud, put her patient 'on the road that leads from her fantasy life back to reality'. ${ }^{23}$ Like Sigmund Freud, who wrote that even if an individual were to communicate his or her phantasies they would leave the listener cold, Anna Freud recognized the role of language in transforming the affects that accompany the daydream. Outside the psychoanalytic encounter, fantasy thoughts are placed within a more linear, textual framework that flattens the dynamic nature of such thinking. ${ }^{\text {iv }}$

Taking these three texts together, we might relate the suspicion of everyday introspective accounts of mind wandering at least in part to the complex relations tying daydream and fantasy to the written word. Language, embedded within distinct social contexts, is in many ways considered duplicitous in relation to the contents of consciousness. Even if literary techniques, such as Woolf's, attempt to evoke the rhythms and affects characteristic of the wandering mind, writing itself is the site of an opacity that accompanies the unfurling of inner life into the social world. As James noted more than a century ago, the 'lack of a word' imposes limitations on language's ability to represent inner experience, complicating any straightforward relationship between experience and expression..$^{24}$

\footnotetext{
iii Cf. Chap. 10.

iv Cf. Chap. 6.
} 
Acknowledgements This work was supported by the Volkswagen Foundation.

\section{Notes}

1. Jonathan Smallwood and Jonathan W. Schooler, 'The Restless Mind', Psychological Bulletin 132, no. 6 (2006): 947.

2. Jerome L. Singer, The Inner World of Daydreaming (New York: Harper, 1966), 6 .

3. See also Anthony Jack and Andreas Roepstorff, 'Introspection and Cognitive Brain Mapping: From Stimulus-Response to Script-Report', Trends in Cognitive Sciences 6, no. 8 (2002): 333-39; Felicity Callard, Jonathan Smallwood, and Daniel S. Margulies, 'Default Positions: How Neuroscience's Historical Legacy Has Hampered Investigation of the Resting Mind', Frontiers in Psychology 3 (2012): 321.

4. Jonathan Schooler and Charles A. Schreiber, 'Experience, Meta-Consciousness, and the Paradox of Introspection', Journal of Consciousness Studies 11, no. 7-8 (2004): 17-18.

5. Jerome L. Singer, 'Daydreaming, Consciousness, and Self-Representations: Empirical Approaches to Theories of William James and Sigmund Freud', Journal of Applied Psychoanalytic Studies, 5, no. 4 (2003), 464.

6. William James, The Principles of Psychology. Vol. 1 (New York: Dover, 1950), 244.

7. Ibid., 195.

8. Callard, Smallwood, and Margulies, 'Default Positions', 3.

9. Ibid.

10. Sigmund Freud, 'Creative Writers and Day-Dreaming' (1908), in The Standard Edition of the Complete Psychological Works of Sigmund Freud, trans. and ed. James Strachey (London: Hogarth Press: The Institute of Psycho-Analysis, 1953-74), 9: 144-45.

11. Ibid., 144-5.

12. Ibid., 146-7.

13. Ibid., 152.

14. Virginia Woolf, The Mark on the Wall (Richmond, Surrey: Hogarth Press, 1919), 4.

15. Ibid., 1.

16. Ibid., 5 .

17. Ibid.

18. Ibid.

19. Anna Freud, 'The Relation of Beating-Phantasies to a Day-Dream Freud' (1923), in Introduction to Psychoanalysis: Lectures for Child Analysts and Teachers, 1922-1935 (London: Hogarth Press and The Institute of PsychoAnalysis, 1974), 154-5.

20. Ibid., 157. 
21. Ibid., 146.

22. Ibid., 154-5.

23. Ibid., 157.

24. James, The Principles of Psychology. Vol. 1, 195-6.

\section{FURTHER READING}

Callard, Felicity, Jonathan Smallwood, Johannes Golchert, and Daniel S. Margulies. 'The Era of the Wandering Mind? Twenty-First Century Research on Self-Generated Mental Activity'. Frontiers in Psychology: Perception Science 4 (2013): 891.

Corballis, Michael C. The Wandering Mind: What the Brain Does When You're Not Looking. Chicago: Chicago University Press, 2015.

Freud, Sigmund. The Interpretation of Dreams. Translated by Joyce Crick. Oxford: Oxford University Press, 1999.

Schooler, Jonathan W., Jonathan Smallwood, Kalina Christoff, Todd C. Handy, Erik D. Reichle and Michael A. Sayette. 'Meta-Awareness, Perceptual Decoupling and the Wandering Mind'. Trends in Cognitive Sciences 15. no. 7 (2011): 319-26.

Woolf, Virginia To the Lighthouse. Edited by David Bradshaw. Oxford: Oxford University Press, 2006.

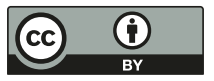

This chapter is distributed under the terms of the Creative Commons Attribution 4.0 International License (http://creativecommons.org/ licenses/by/4.0/), which permits use, duplication, adaptation, distribution and reproduction in any medium or format, as long as you give appropriate credit to the original author(s) and the source, a link is provided to the Creative Commons license and any changes made are indicated.

The images or other third party material in this chapter are included in the work's Creative Commons license, unless indicated otherwise in the credit line; if such material is not included in the work's Creative Commons license and the respective action is not permitted by statutory regulation, users will need to obtain permission from the license holder to duplicate, adapt or reproduce the material. 